\title{
REVERSIBILITY
}

Desmontando la mega-ciudad efímera más grande del mundo Disassembling the biggest ephemeral mega city

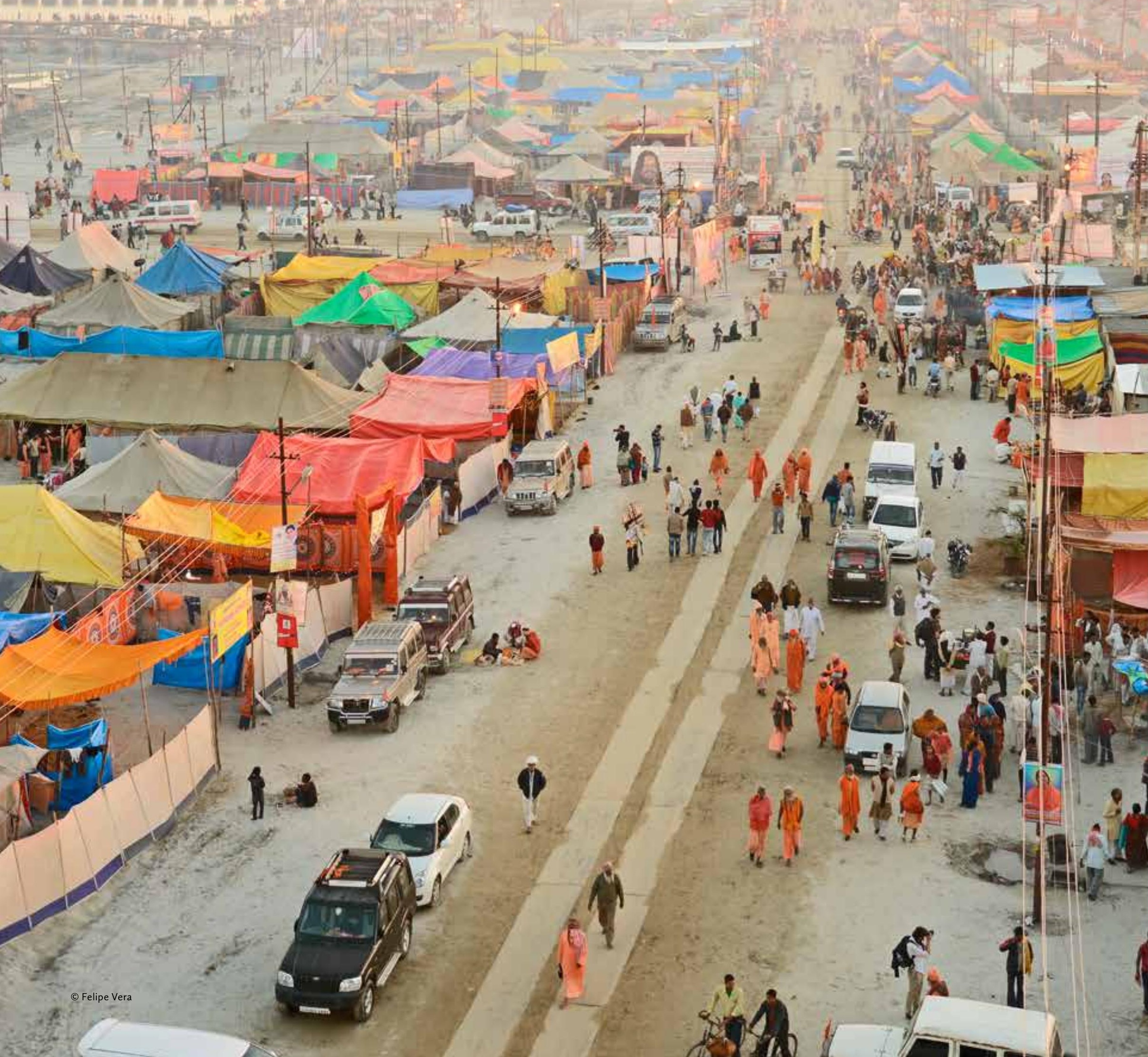




\section{Rahul Mehrotra}

Chair Department of Urban Planning and Design, Graduate School

of Design, Harvard University, Cambridge, MA, USA

\section{Felipe Vera}

Co-director, Centro de Ecología, Paisaje y Urbanismo, Universidad Adolfo Ibáñez, Santiago, Chile

It seems incredible but it's true. In India, there is an ephemeral mega-city, which lasts five weeks, and which is then completely dismantled until its new assembly. This research not only tells the story of this impressive example of reversible urbanism, but also analyzes the key facts and logics -administrative and materialthat allow the city to function with a flexibility we would hardly associate with an urban settlement, even less if it hosts up to 7 million inhabitants.

KEYWORDS · India, Kumbh Mela, urbanism, ephemeral, informal

SIXTH ReCOMmendation: Design 'light, temporary, reversible infrastructure'; build roads, bridges, connections with non-rigid, non-definitive, removable logistical systems that leave no trace on the ground and adapt to the change of local needs over time.

(Branzi, 2015:26)

The physical structure of cities around the globe is evolving, morphing, mutating and becoming more malleable, fluid, and open to change than the technologies and social institutions that generate them. Today, urban environments face ever-increasing flows of human movement, acceleration in the frequency of natural disasters, iterative economic crises that modify streams of capital and their allocation as physical components of cities. As a consequence, urban settings are required to be more flexible in order to be better able in responding, organizing, and resisting external and internal pressures. At a time in which change and the unexpected are the new normal, urban attributes like reversibility and versatility seem to be critical elements in thinking about the articulation of a more sustainable form of urban development. The case of the Kumbh Mela and the lessons we can extract from it are clearly aligned with these attributes.

\section{KUMBH MELA IN CONTEXT}

As Warren E. Fusfeld points out, we can find traces of the Kumbh Mela as regular religious practice around the sixth century BC. It started as a military strategy promoted by religious hierarchies and since its inception it was very related with politics and economic interests (Fusfeld, 1974). The naga babas ${ }^{1}$ during the time of the mogul emperor Akhbar were ascetic militants. Lochtefeld even describes them as a possible resource for the empowerment of the emperor; he actually argues that:

The ultimate origins of ascetic militancy are uncertain. One well-known story attributes their origin to the repeated attacks on scholarly Hindu

1 Naga Babas are naked gurus that had been often depicted by the press as the spectacle of the Kumbh Mela. 


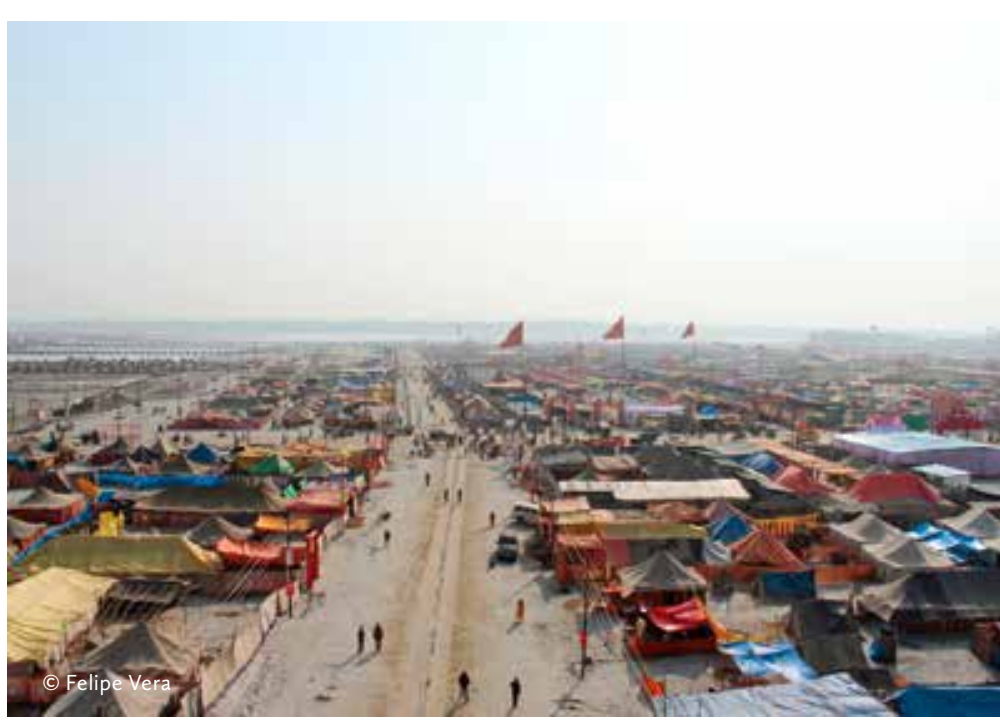

1) 1.1

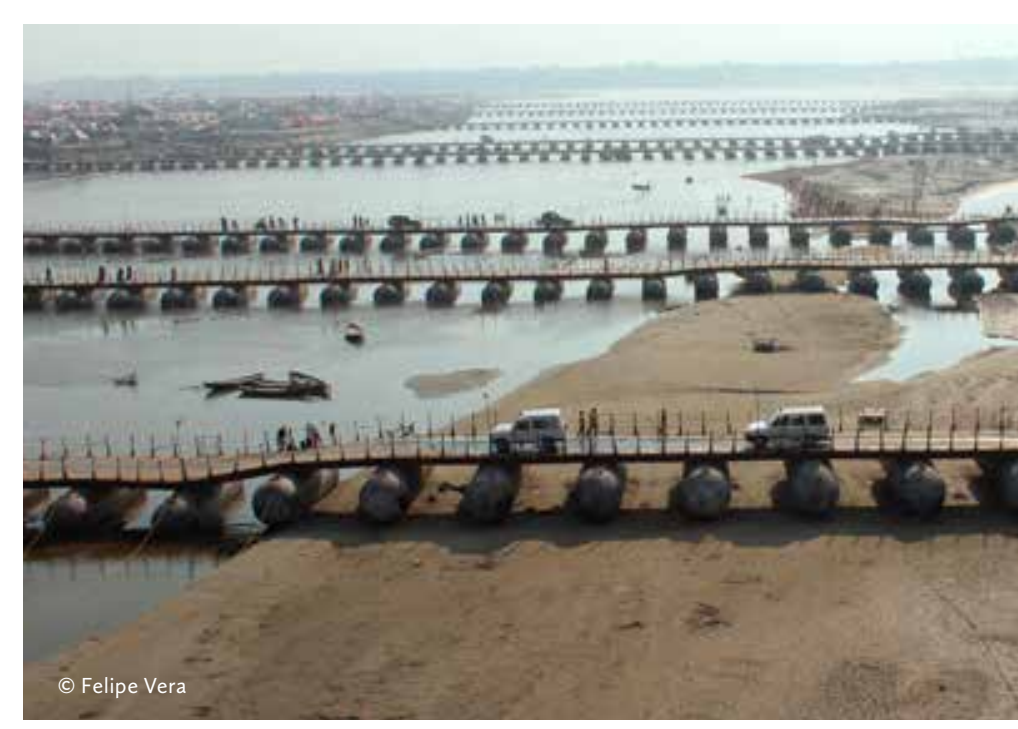

ascetics by Muslim faqirs. This story relates that in 1565 the eminent sannyasi leader Madhusudana Saraswati went for help to Birbal, a Hindu adviser to the Moghul Emperor Akbar. Birbal suggested that ascetics initiate non-brahmins into their orders, as fighting men to protect the scholars. Akbar himself approved this suggestion, which was immediately carried out. (Lochtefeld, 1994:590)

The festival itself started being described in detail for the first time by Hsuan Tsang a Chinese traveler who passed through India in the late six hundreds. ${ }^{2}$ After that the Melas ${ }^{3}$ have been in one way or another present in historical registers. Actually in the last version there was an archival exhibition with historical images and drawings mounted by the administration. However, the most meaningful explanation is not the historical but the one that relies on the memory of Hindu people built by both experience and legends. The mythological origin of the festival comes from a legend which describes a battle between gods (devas) and demons (asuras), where four drops of the sacred nectar of immortality -Amrit- fell in the four cities in which the festival is now performed. It is said that when the relationship between the planet Jupiter and the Sun replicates the celestial map that witnessed the battle, the sacred rivers in which the drops fell acquire the power of providing enormous spiritual benefits. It is under these conditions when millions of pilgrims gather during the month of Magha ${ }^{4}$ to dwell on the site of the Kumbh. Holy men, devotees, pilgrims, foreigners and every kind of people get together in the world's biggest public gathering to receive these sacred benefits.

The Kumbh Mela is even more important, sacred, and visited when it happens at Allahabad, at the confluence of three sacred rivers. Today two of these rivers are visible, the Ganges and the Yamuna, while the third is a mythical river named Saraswati which appears only in the sacred texts, and is currently assumed to flow underground. The attention given to this festival in relation to other points of pilgrimage in the Puranas and Vedas ${ }^{5}$ legitimize its importance since the Gupta period. Saraswati (1975), Dubey (2001), and Eck (2012) have contextualized this interpretation in the idea of India as a 'sacred geography' formed by a network of places, which are repeated and replicated in relation to each other throughout the country. Holy narratives relating gods and their events with a particular geography

\footnotetext{
2 For more information check Travels of Hsuan-Tsang - Buddhist Pilgrim of the Seventh Century, by Irma Marx (1997), accessible at the website of the Silkroad Foundation in http://www.silk-road.com/artl/ hsuantsang.shtml

3 Mela is the denomination for a religious gathering in Hindu tradition.

4 The month of Magha is the month that starts every year when the sun enters Capricorn and according to the Hindu calendar it is the eleventh month of the year.

5 The Vedas and Puranas are Hindu religious texts.
} 


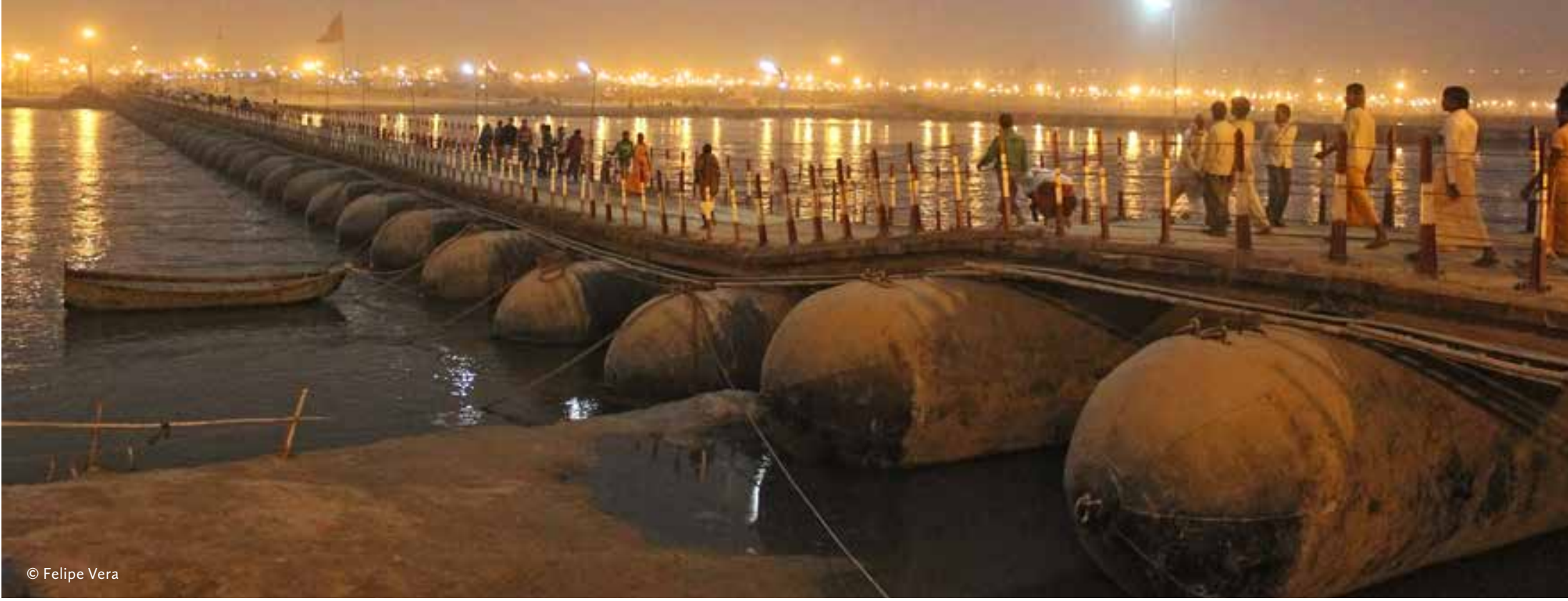

-and therefore connecting sacred places- called them tirthas, which are conceived as points in which the thresholds between the divine and the mundane get blurred (Bakker, 1990; Dubey, 2001; Eck, 2012). Among the tirthas Allahabad has the category of tirtharaja that means "the king of the sacred places." This place is said to be the holiest place of the three worlds: heaven, earth, and netherworld (Dubey, 2001:12). Prayaga (original name of Allahabad) is also known as the Triveni, which means the encounter of three sacred rivers Ganga - Yamuna - Saraswati. In this way also the Kumbh Mela, which is held also in three other cities, (Haridwar, Nashik, and Ujjain) is the most crowded, considered the most sacred, and acquires a special significance when it happens at Allahabad.

At Allahabad people come to the Triveni ${ }^{6}$ every year in the month of Magha to take a holy bath in the confluence of the rivers, but every twelve years, the bath achieves an incomparable scale making this annual bath at the Kumbh Mela very special. This convergence situates Allahabad among one of the three mayor tirthas of India along with Kasi (Varanasi) and Gaya (Ayodhya) (Acharya, 1997). "The land between the Ganga and the Yamuna is said to be the mons veneris of the goddess Earth and Prayaga is regarded as its generative organ. This is a cosmogony allusion to the place suggesting that Prayaga is the mythical Centre of the creation of the universe" (Dubey, 2001:14). The region between the Ganges and the Yamuna was also the place in which the Aryan and indigenous merged becoming a political center for several great imperial dynasties. Eck shows in her work 'India a Sacred Geography' how the importance of sacred places can be verified in its potential to be repeated. Prayaga (Allahabad) had been repeated in other places of India giving name to other cities. Prayaga as Kasi (Varanasi) is also a place where people go to receive Moksa (Liberation), therefore beggars, pilgrims, peasants and kings go to this place to bathe in the sacred junction.

Besides its sacred nature, this massive gathering, resulting in the biggest ephemeral megacity in the world, generates an extreme case of ephemeral urbanism forcing us to deeply reflect about the way we think 


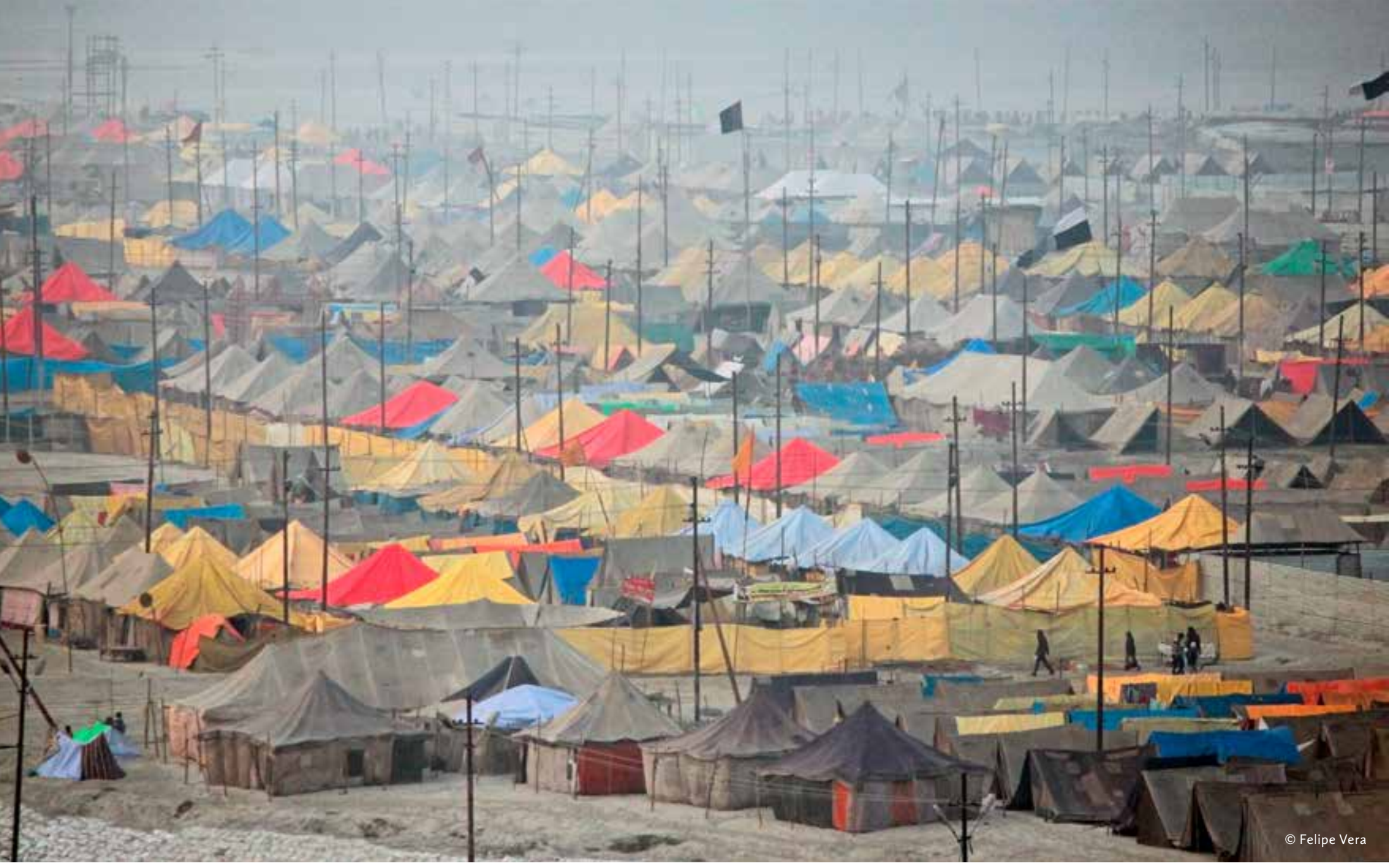

of cities more broadly and from which several lessons and ideas can be extracted. This essay reflects upon a key attribute of the ephemeral city of the Kumbh Mela, its reversible condition, and the lessons we can extrapolate from it for architecture, urban design, and planning in the contemporary world.

\section{REVERSIBILITY}

The city of the Kumbh Mela challenges the idea of sustainability, as the anxiety for preserving equilibrium, by engaging us to think of urban design as a reversible operation. Upon examining the stunning images of the ephemeral city, we tend to fix the eye on the incommensurable expansion the city undergoes when it is in operation. However, what is most remarkable about the Kumbh Mela is not that it is only constructed in such a short period of time, but also that it has the ability to be disassembled as quickly as it was built. The Kumbh Mela raises a nuanced set of questions about how reversibility could be better imagined in the production of future cities. In a matter of weeks, the biggest public gathering in the world deploys its own roads, pontoon bridges, cotton tents serving as residences and venues for spiritual meetings, and a 

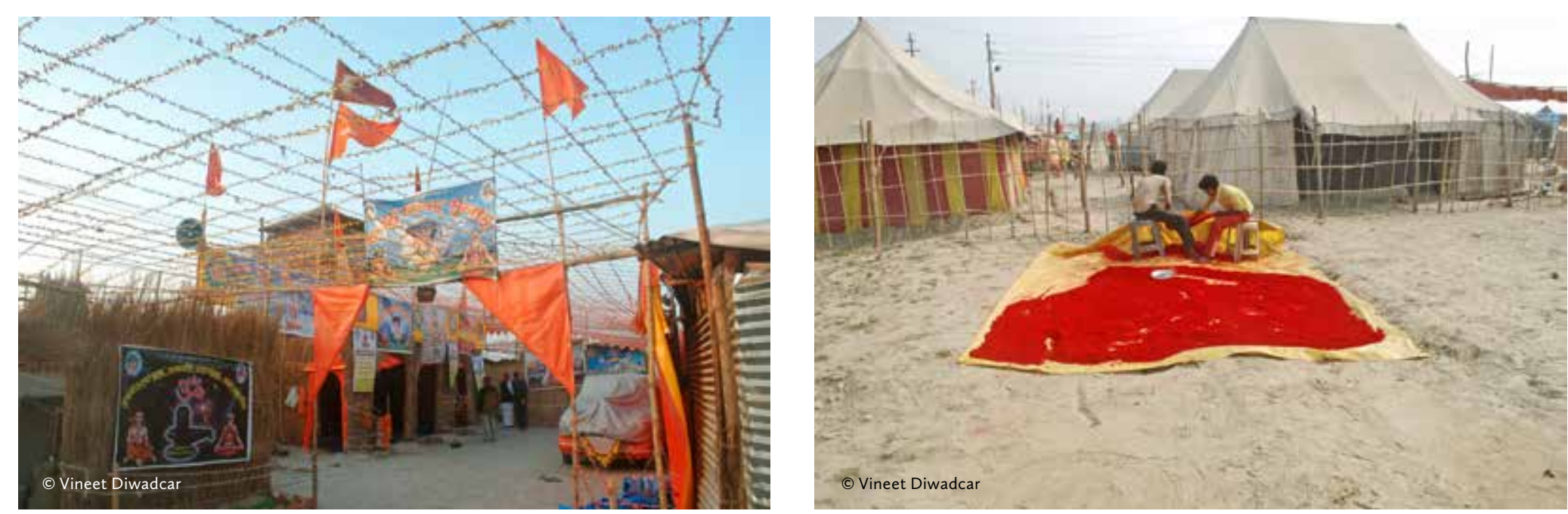

\section{"(...) what is most remarkable about the Kumbh Mela is not that it is only constructed in such a short period of time, but also that it has the ability to be disassembled as quickly as it was built."}

spectrum of social infrastructure -all replicating the functions of an actual city. This pop-up megacity serves approximately 5 to 7 million people who gather for fifty-five days and an additional flux of 10 to 20 million people who come for 24 -hour cycles on the five main bathing dates. Once the festival is over, the whole city is disassembled as rapidly as it was deployed, reversing the constructive operation, disaggregating the settlement to its basic components, and recycling a majority of the material that was used.

Without seeing images of the Kumbh Mela, one could hardly believe that a complex megacity of such extensive scale could be deployed in such a short and compressed time span, even with all the technological instruments and disciplinary knowledge that we currently possess. However, it is precisely in the lack of technological specificity and reversibility as an a priori constraint for deployment, where its robustness lies. Therefore, one of the most valuable lessons offered by the Kumbh Mela is the implementation of tactics that allow the deployment of a whole city as a 'holding strategy' for temporary urban processes, which do not aspire to be permanent. It is the non-permanent solution for a nonpermanent problem where the raison d'être of the city lies. This alignment between the temporary nature of the problem -in this case, to host millions of people for fifty-five days- and that of the solution is something we could and perhaps should incorporate as a basic protocol for the cities we reshape and create in the future.

Reversibility can be examined in two contrasting dimensions, material and immaterial. Its material aspects, which translates in the physical reversibility of the constructed armature, supports the existence of the Kumbh Mela, while its immaterial aspects frame a reversible political and institutional structure that supports the construction and organization of the ephemeral city.

In the context of more permanent settlements, institutions associated with urban processes take time to form and are not often created as malleable and flexible structures. However, in the case of the Kumbh Mela, a flexible temporary governance system is created to act as a surrogate 


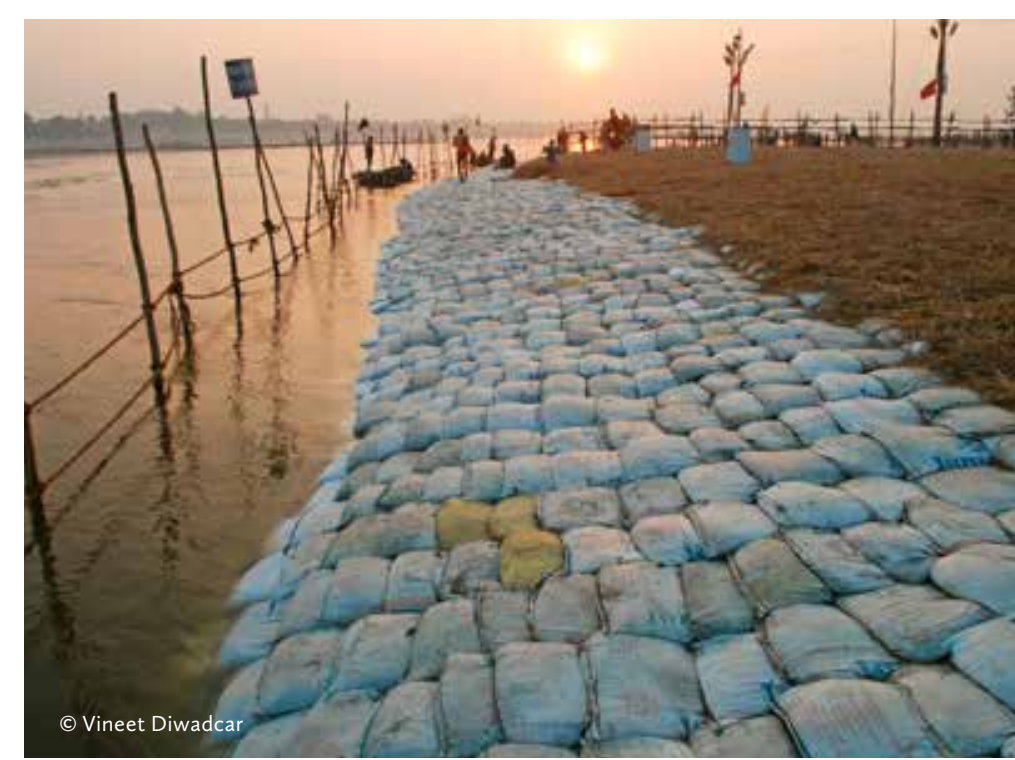

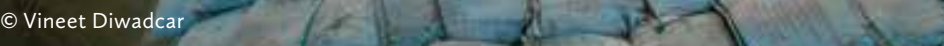

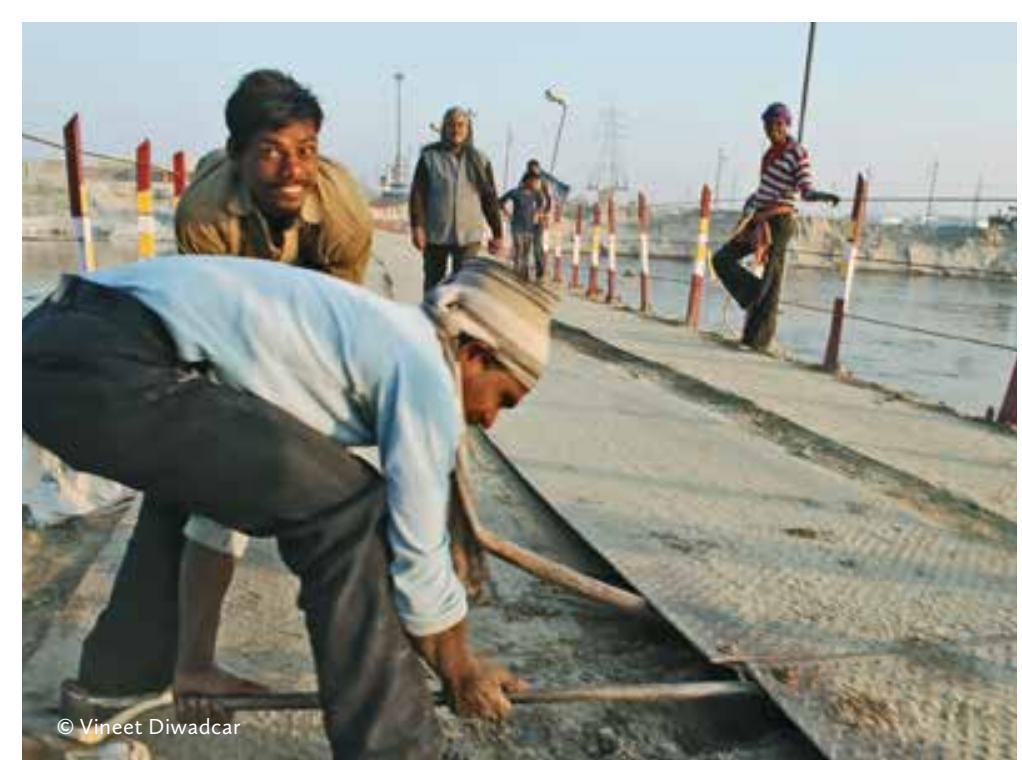

for what might have been more permanent. This system of governance plugs into a pre-existing urban management organization at state level and draws its expertise from existing institutions, often pulling together (for a short period of twelve months), the best administrators in the state. During the festival, the institutional framework of the Kumbh Mela becomes an autonomous city managed by several temporary governmental agencies that have jurisdiction over the site. ${ }^{7}$ The institutional structure that manages the city evolves depending of the stage in which they operate. The deployment of the city is then divided in four main stages that affect the nature of its governance. The first phase is used for the initial stage of planning, which is held outside the physical space of the Kumbh, and involves government authorities that range from a local to a national level. The second stage is for implementation which happens both in the peripheries of the site while the river is still high and on site when the river Ganges and Yamuna recede. Management is the third stage of the deployment, which corresponds to the period in which the city is in operation, which not only includes the challenge of handling the massive crowds of people, but also the oversight of a river that might fluctuate or shift in its trajectory by thirty feet per day. Finally, the disassembling stage starts after the last bathing day of the Kumbh Mela, which reprograms the space into agricultural fields for a few weeks before the Ganges floods again in the monsoon to reclaim the site of the city.

The administration of the city is implemented by an organizational structure that is not only impermanent -something one could expect given the temporal condition of the city- but also flexible, allowing the progressive appearance of transversal links of communication across diverse hierarchies. This is clear when one examines the nature of the meetings and the authority each member has during different moments of the city's deployment. Relations of power and connections vary depending on the stage of the deployment. During the planning stage, interactions are framed in departmental meetings that are small in scale with the authority mostly residing among representatives of the state. During this process, the state of Uttar Pradesh engages twenty-eight departments as well as seven different central departments from the national government. Over time, once the implementation stage begins, the governance system gets more dynamic, articulating constituencies at different levels that are represented on site. During this stage, diverse mechanisms of feedback among different levels within the hierarchies get set up in order to deal with the need for quick decisions of adjustment in the materialization of the plan. The dynamism of the structure reaches its

7 The United Provinces Mela Rules are public and accesible at: http://kumbhmelaallahabad.gov.in/ pdf/Mela_rules_1940.pdf 

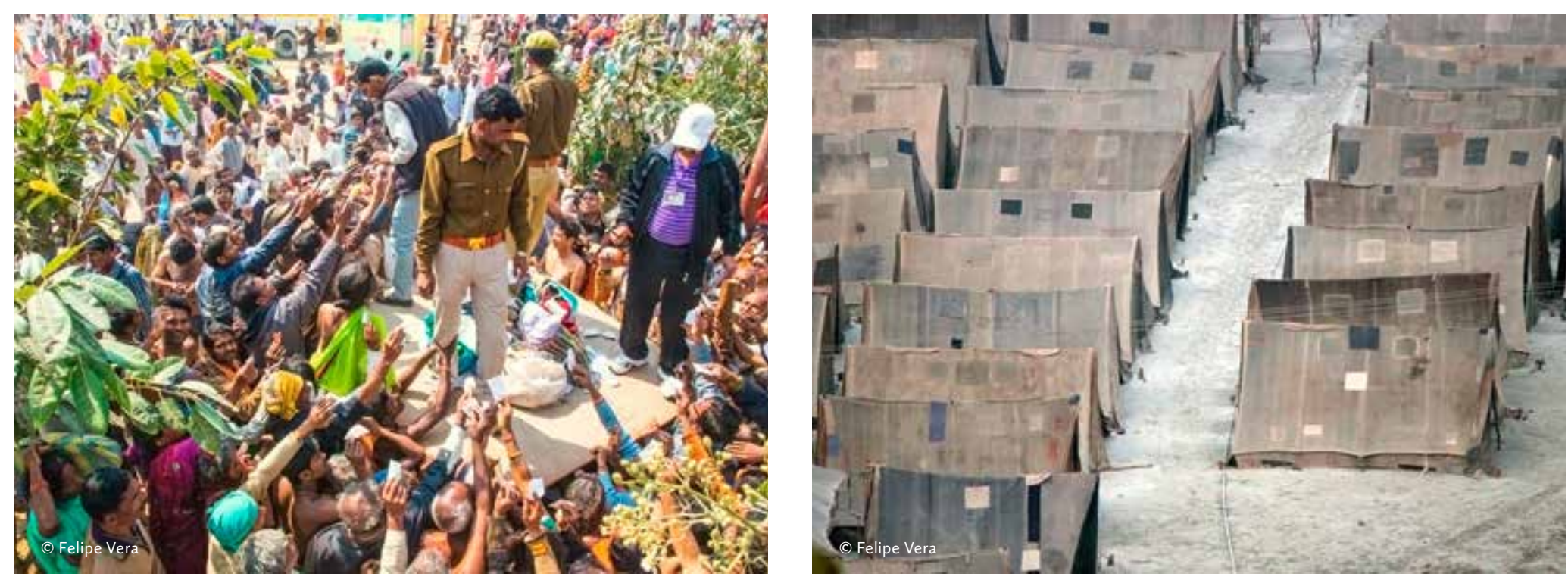

climax while the city is in operation. At this time, authority shifts from the high levels of the pyramid that operate at state and regional levels into the grounded administration of the Kumbh. Crucial is the fact that the Kumbh administration meets on the ground each evening during the festival in a dynamic that connects with every single level of the otherwise hierarchical administrative structure. This gives the administrator of the event the capacity to react to any unpredicted incidents or requirements quickly and effectively, bypassing inefficient clearance processes when necessary. Once the whole process is over, administrators are often promoted or reappointed in the pre-existing governmental structure. Once the river washes over the terrain due to the flooding from seasonal monsoon rains, the institutional framework that enabled such an enormous operation vanishes like the traces of the city.

Reversibility is also the main attribute that supports the physical deployment of the city. The implementation strategy, which is generic and employs low-tech construction techniques, facilitates the shaping of the most amazing buildings and morphologies, leaving open the possibility of reversing such operations once the festival is finished. This also allows the materials to be recycled by their reincorporation into regional economies and local industries. The few building techniques implemented at the Kumbh are based on the repetition and recombination of a basic module with simple inter-connections. This is usually a stick (approximately 6 to 8 feet long) that by aggregation generates diverse enclosures in a wide range of forms from small tents into complex building paraphernalia, providing expression to various social institutions such as theaters, monuments, temples, hospitals, etc. All of them are constructed out of the same elements: bamboo sticks used as the framework and laminar materials such as corrugated metal and fabric. The simplicity of the building system not only facilitates the attributes for assembly, reconfiguration, and disassembly on site, but also facilitates the logistics and channels of distribution for each component and piece. One person or groups of people provide the modulation of every material in a way that can be carried and handled in absence of heavy machinery. Material components are small and light enough to be easily transported and distributed to every corner of the settlement in a rapid and efficient manner facilitating both construction and reconstruction, as well as formation and reabsorption into the various ecologies and geographies of the region. Everything is constructed and afterwards disassembled with equal ease.

The entire Kumbh nagri starts to get dismantled after the last major bathing day, which was on February $17^{\text {th }}, 2013$ during the last cycle. Since it rained heavily during this time period -over a period of three days- some of the Akharas, Ashrams, and Kalpavasis decided that it was 


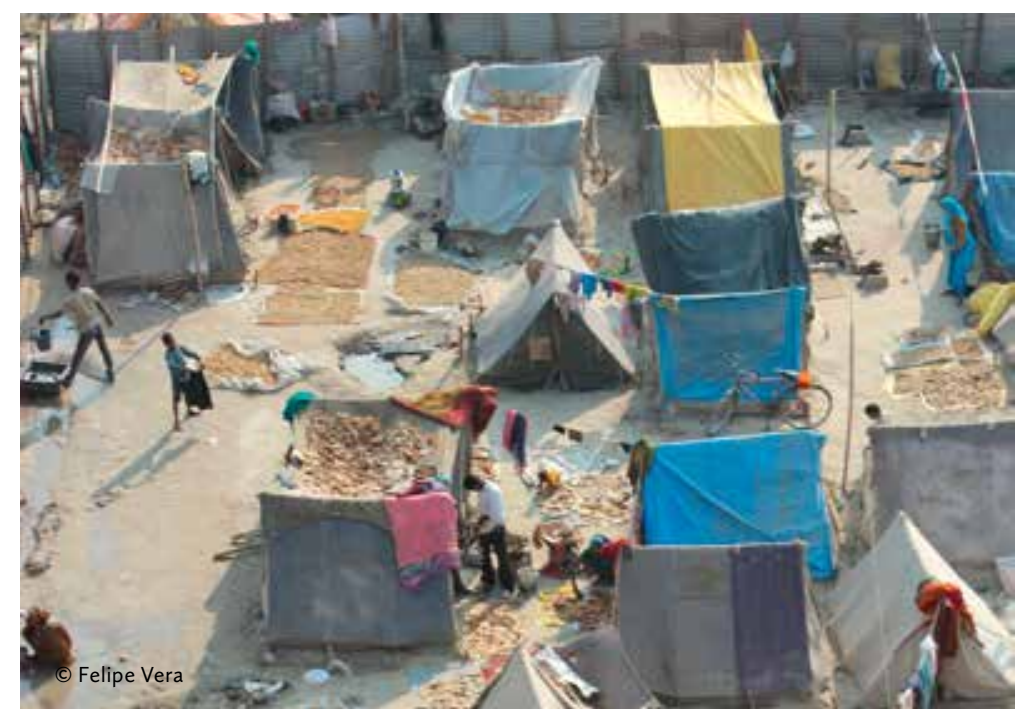

better to leave earlier than other years. The rain also caused flooding in sector seven and eight, drenching tents. However, most of the people left the site between the $20^{\text {th }}$ and $26^{\text {th }}$ of February. By March 1oth, which is the last bathing day, only a few private groups of dwellers were still at the Kumbh and participated in the bathing. The emptiness of what was before a full functioning city was by early March, largely unoccupied, except for the government structures that were still in place. However, several visitors still came in for a day or two. By March $16^{\text {th }}, 2013$, only half of the governmental structures were still standing, most of which were electricity board structures.

The disassembly of Akhara and Ashrams' camps started with the devotees taking their things by different means -cars, trucks, or tractors- while chief organizers of each religious order and their chelas (followers) stayed until the last day. When a religious order is ready to leave the Kumbh, they get in touch with the contractor that constructed their camp. They do this either directly, if they paid for the camp themselves, or through the sector magistrate, if the camp was constructed with funding from the Kumbh Mela administrator. Days are arranged when trucks and workers arrive to remove all the material: the tents, the plywood, the steel sheets that formed fences, and every other component of the camp. Once disassembled, the material is taken to the compounds to be stored, counted, and sorted for damaged pieces. After that, the elements are sent to different suppliers all over India in trucks, with each one carrying one specific type of material.

A large part of the common infrastructure is also disassembled once the Kumbh is over. For instance, by digging up wastewater and water supply pipes, Jal Nigam Contractors removed all of the tap connections. In the same way that tents are deconstructed and separated by materials to be returned to their original supplier, tap connections, motors, and pipes are returned to the Jal Nigam store from which they were originally ordered. Once disaggregated, the material is reused in different locations of Uttar Pradesh in other Jal Nigam projects. A meter-long pipe is then welded as an attachment to the tube wells, in order to extend their height and prevent the river from filling them up.

Part of the common infrastructure remains on site. Sewage pits, for instance, are uncovered from their bamboo structures, treated with chemicals and covered with sand; the same is done with water reservoirs. Other kinds of infrastructure, like sandbags and toilets, get removed. Toilets are one of the most dispersed infrastructures built by the Kumbh Mela administration. The sweeper community oversees toilet removal; they take the ceramic seats to the main health store while the rest of the brick and bamboo is sold to different contractors to be reused in other locations. The same happens with electricity infrastructure. Wires are taken down and wound, poles are disassembled dividing them in concrete 


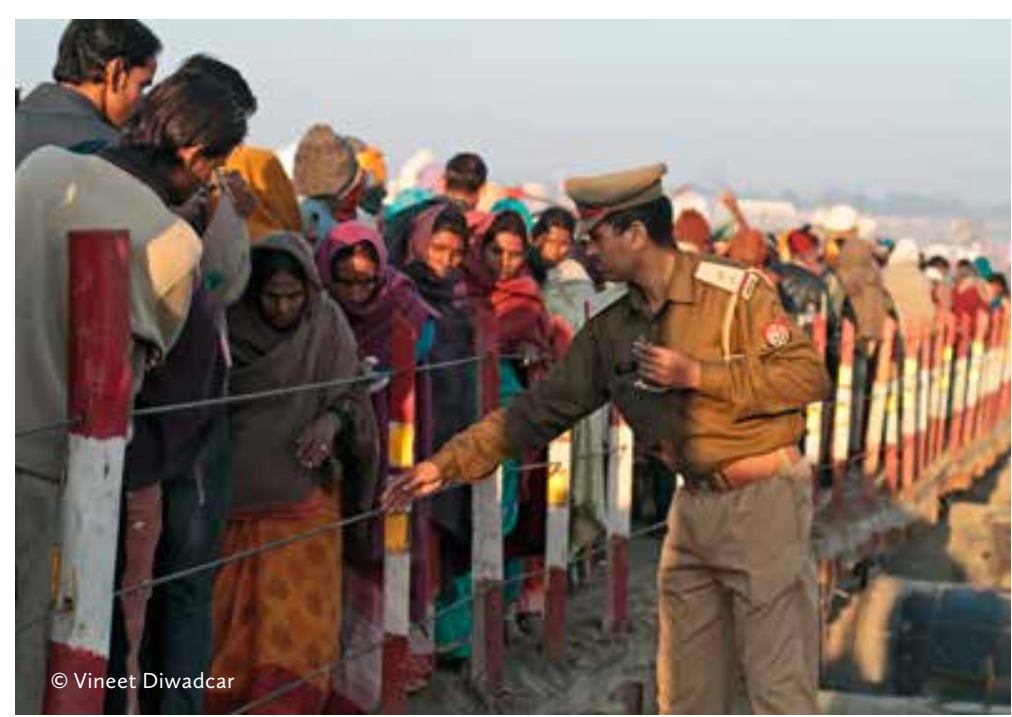

\section{"Once disassembled, the material is taken to the compounds to be stored, counted, and sorted for damaged pieces. After that, the elements are sent to different suppliers all over India (...)"}

parts, and metal pieces are taken back to storage. Special electricity boards keep a digital inventory of every registered item.

Roads and pontoons are taken apart sector by sector and brought to three main storage locations in the area: one in the parade ground, the second near the railway yard, and the largest in Jhusi, next to the bus stand. Bridges are broken up in parts, first the railing, then the plates, and finally the joist and pontoons. Once all the material is disassembled, the state government decides where to apportion the bridges and roads. This depends on the different district needs (for instance, villages with mud roads that are prone to flooding). Once these decisions are made, the infrastructure is distributed and reconstructed in diverse locations of Uttar Pradesh.

Not only does the construction material get reused after the Mela ends, but even waste becomes a resource to be taken off site. A large number of scavengers from areas in and around Allahabad arrive at the site. They dig up waste coal dumped by community kitchens to use as fuel; they empty the sand bags from which the ghats were constructed to make ropes. They take any discarded wood or bamboo to burn on their fires. Scavengers take almost everything, cleaning up the site completely.

After all the material is removed, the flood plain of the river is still a landscape full of patterns, dots, and traces of the city. It is possible to see a big range of elements, from bricks and toilets that are unusable, to altars that remain as a fleeting trace. Big statues are taken away but their brick plinth remains on site with some small sacred statues like shiva lingams and other minor statues that were not taken away. Organic material that is left behind, such as sandbags and bamboo poles, gradually disintegrates with time.

Once the disassembly activity is over, the site reestablishes its natural, annual patterns. People from nearby villages prepare beds for planting seasonal vegetables, like cucumber and gourds. Thick grass or thatch that served as the matting for the tent floors is usually burned, making the soil more fertile. Small wells are also built near creating a bountiful 


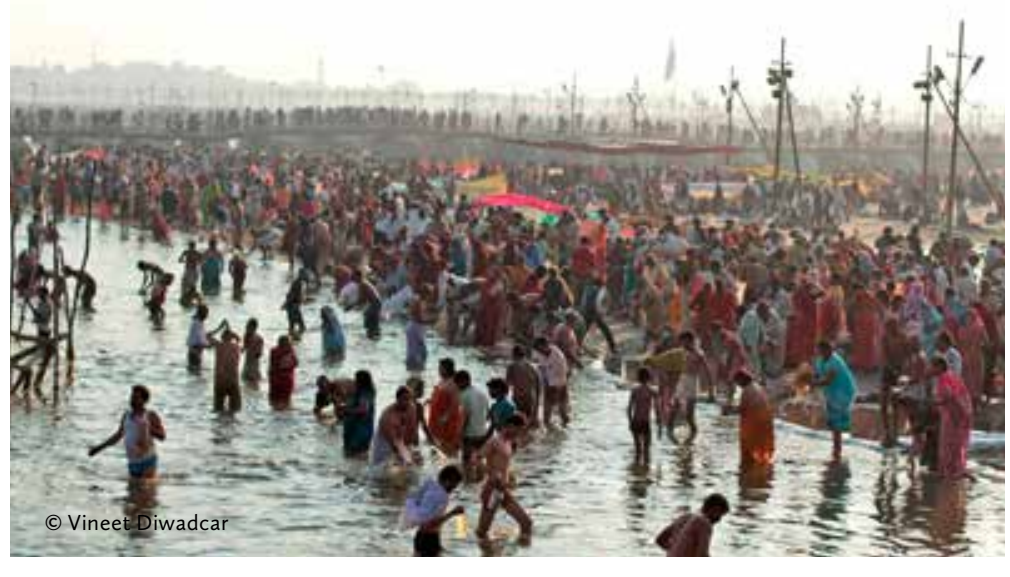

agricultural site. The cremation ground on Sector Five is eventually overtaken with vegetation and the river's edge is recolonized.

Reflecting on the processes described above, one is reminded that the most revolutionary opportunities for redefining the ways we produce the built environment, lie in much simpler, low-tech tactics. Multiple, highly heterogeneous structures are organized around combinatory systems that rely on minimal building strategies. Their construction techniques allow greater degrees of flexibility. The generic condition of its basic elements -sticks connected by rope, or simple nails in both orthogonal and diagonal relationships- offer infinite possibilities of recombination. The strength is in the capacity of achieving specific and determinate forms with a couple of indeterminate solutions that are applicable in different contexts and adjustable at any moment. On account of this kit-of-parts approach, the material used for erecting tents, gathering spaces, and constructing monuments that are several meters high, is then reused in other constructions.

In a way, this reversible condition becomes a counterpoint to our contemporary building culture, being the only aspect that has been notoriously absent from the current debate over what to do with the afterlife of 'built-things' we perceive as not useful anymore. Today buildings are constructed to last as long as possible. We usually don't consider the eventual need for transformation, meaning that the provision of options for reconfiguration, in cases of obsolescence, is not appropriately factored in the designs. We have developed a highly articulated technique for constructing and assembling all sorts of structures, which allow us to handle more complex and efficient construction processes. However, very little has been imagined in relation to progressing in the development of more efficient ways to disassemble and deconstruct the things we build. Paradoxically, what we can learn from the Kumbh Mela is that the most unsustainable practices do not rely on the construction of the built environment, but rather in how inefficient we are with the reconfiguration of space that is already built. Unfortunately, in more permanent settings, demolition has been the generalized answer for opening up space that the city requires for growth and adapting to new needs. In short, the lack of incorporation of disassembly strategies as an inherent part of the design imagination together with construction protocols- obstructs the fluid and sustainable metabolism of contemporary urban space.

\section{TOWARDS A MORE NUANCED TEMPORALITY}

After studying the Kumbh Mela, one could then suggest that urbanism and design on a wider spectrum, could move towards more nuanced ways for effectively factoring in temporalities as critical components of institutional and technological orthodoxy. To engage in this discussion, the exploration of temporal landscapes like the Kumbh Mela might open potent paths to 
